\title{
LA AGRICULTURA Y LA INDUSTRIA ESPAÑOLAS DE FINALES DEL XVIII: CAMPOMANES Y JARDINE
}

\author{
José Francisco PÉrez BERENGUEL \\ Universidad de Alicante
}

Mucho pueblo, ocupado utilmente todo; y una industria animada incesantemente por todos caminos [...] son los dos principios seguros y fecundos del engrandecimiento de una nacion. ${ }^{1}$

CAMPOMANES

Fecha de recepción: octubre de 2009

Fecha de aprobación: febrero de 2010

\section{UNA NUEVA CIENCIA: LA ECONOMÍA}

Adam Smith señalaba que «el gran objeto de la economía política es incrementar la riqueza y el poder» de las naciones. ${ }^{2}$ Por tanto, dos son los objetivos primordiales que ésta debería perseguir: crear las condiciones para que el pueblo pueda conseguir abundantes ingresos, y proporcionar al Estado una cantidad de dinero suficiente para hacer frente a los servicios públicos. El conocimiento de esta nueva ciencia, tan propia del racionalismo y la Ilustración, se había constituido en uno de los objetivos primordiales de personas como Campomanes o Alexander Jardine. ${ }^{3}$ La economía se había

1. Campomanes, Conde de [Pedro Rodríguez-Campomanes]: Discurso sobre el fomento de la industria popular, Madrid, Antonia de Sancha, 1774, clxxxv.

2. SMith, Adam: La riqueza de las naciones, Madrid, Alianza Editorial, 1994, p. 476.

3. Alexander JARDINE (-1799) fue el autor de Letters from Barbary, France, Spain, Portugal, \& c. (London, T. Cadell, 1788), y Cartas de España (Edición crítica, traducción y notas de José Fco. Pérez Berenguel. Alicante, Publicaciones Universidad de Alicante, 2001), donde nos cuenta sus impresiones sobre la realidad política, social y económica de España. Todos los pasajes citados en el presente artículo pertenecen a la edición traducida de sus Cartas de España. Una información más detallada del personaje aparece 
convertido así en un arma para restablecer la nación y para engrandecerla y, por ende, en un instrumento de la mayor importancia para los sucesivos gobiernos ilustrados.

España difícilmente podía permanecer ajena a esta corriente que invadía toda Europa. Estos temas se habían hecho recurrentes en muchas reuniones sociales y tertulias, lo que suponía, según Jardine, que ahora eran mejor entendidos que antes, por lentos que fueran los gobiernos a la hora de aplicar muchas de las medidas propuestas. El mejor testimonio de lo frecuente que eran este tipo de conversaciones nos los ofrece el Espíritu de los mejores diarios, que se hace eco en uno de sus artículos sobre economía política de una discusión sobre el tema habida en una tertulia. ${ }^{4}$ Esto no suponía nada más que una señal de cómo algunos ilustrados españoles empezaban a estar al corriente de las opiniones de muchos de los principales economistas extranjeros. La economía política se convertía, en fin, en la ciencia natural de la sociedad, y sus principios mostraban el camino a seguir para vivir y prosperar en una sociedad moderna sometida a los dictados de la razón. Valentín de Foronda llegaría incluso a considerarla «la benéfica ciencia que se propone mantener a las sociedades». ${ }^{5}$

Dos cuestiones jugarían un papel más destacado en la doctrina económica de Adam Smith: la división del trabajo y el cultivo de la tierra. La división del trabajo, porque produce los efectos beneficiosos de un mayor progreso de la capacidad productiva, así como una mayor habilidad o destreza en su aplicación, como puede verse en aquellos países que disfrutan de un mayor grado de desarrollo económico; y el cultivo de la tierra, porque representa la parte más importante de la riqueza de cualquier país, y va a estar bien cultivada si el producto de la misma es lo suficientemente elevado como para que el trabajo que se emplea en ella resulte rentable. Por lo tanto, cualquier aumento en la riqueza de la sociedad y, por ende, del trabajo útil empleado en ella, tiende indirectamente a elevar la renta real de la tierra. Además, señala Adam Smith, los beneficios que proceden de una adecuada división del trabajo y de un provechoso cultivo de la tierra tienden a hacerse extensibles a toda la población.

En el caso de Campomanes su posición iría evolucionando con el tiempo, en paralelo con el propio desarrollo teórico de las principales teorías económicas, ya que pasa de un mercantilismo inicial a un cada vez mayor fisiocracia, hasta el punto de acabar criticando las ideas de los mercantilistas y confesar su equivocación anterior: «Disonará mucho este partido, sin duda, á los que se persuaden, consiste la esencial riqueza de una nacion, en acumular los metales de oro y plata. Lo propio me sucedia

en Guerrero Latorre, Ana Clara: Viajeros británicos en la España del siglo XVIII (Madrid, Aguilar, 1990), pp. 70-77; y en PÉREZ BERENGUEL, José Fco.: «La sociedad y las costumbres españolas del XVIII: la perspectiva de Alexander Jardine», en Trienio. Ilustración y Liberalismo, núm. 29 (1997), pp. 5-26; y «Alexander Jardine y la polémica sobre las causas de la decadencia española», en Hispania, LIX/2, núm. 202 (1999), pp. 625-636.

4. «Discurso económico-político sobre los medios de restaurar la industria, agricultura y población de España», en Espíritu de los mejores diarios, 2 de marzo de 1789.

5. Ídem, 6 de julio de 1789. 
á mi, antes de leer, y meditar sobre esta materia». ${ }^{6}$ Evolución que merecería el elogio de Jardine, especialmente cuando señalaba como Campomanes va «abriendo los ojos poco a poco, y sus últimas publicaciones son siempre las mejores». ${ }^{7}$ Este proceso sólo acabará, en su opinión, cuando lea la obra de Adam Smith y se dé cuenta de las deficiencias de su actual sistema de gobierno.

Campomanes consideraba a la agricultura como la forma de actividad económica más rentable, aunque dudaba de que ésta pudiera emplear a todo el mundo, o que pudiera traer consigo una prosperidad completa. El comercio y las manufacturas, al poder emplear a mujeres y a niños, resultaban también necesarias para proporcionar nuevos mercados, para conseguir una balanza comercial positiva y para aumentar la población y el poder del Estado. No obstante, pese a la influencia ya observada de Adam Smith en la obra última de Campomanes, también existían grandes diferencias entre ambos a la hora de plantear algunas cuestiones. El proteccionismo centralizador y estatalista de Campomanes y su falta de atención a la división del trabajo en el desarrollo industrial iban a chocar directamente con las posiciones esgrimidas por Adam Smith. Además, y al contrario de lo que ocurriría con Jovellanos, las ideas de éste quizás le llegaran un poco tarde, toda vez que llevaba ya tras de sí más de veinte años de actividad política e intelectual, y tanto sus dos Discursos como el Apéndice habían sido publicados con anterioridad a La riqueza de las naciones.

\section{INTERVENCIONISMO DEL ESTADO Y FISCALIDAD}

Campomanes era un firme defensor de la supremacía del Estado como regulador de la política económica. En su opinión, le correspondía al soberano poner orden en una sociedad en permanente conflicto entre sus miembros, y conducirla a una situación de prosperidad. Se hacía necesario, por tanto, que todos los estamentos sociales se incorporaran a este proyecto de empresa económica, de la cual iba a depender la felicidad de toda la comunidad. En dicho modelo económico, la iniciativa privada desempeñaba un papel muy reducido, ya que todo estaba supeditado a la consecución del bien común, y éste tenía que ser diseñado con anterioridad por el propio gobierno. Tal planteamiento le serviría para defender el comercio exclusivo de España con las colonias americanas, la manipulación de las aduanas en favor de la industria nacional, o la intervención del propio Estado en todos aquellos órganos que regulaban la actividad económica. Al mismo tiempo, los privilegios de algunas entidades criticadas por Campomanes, como La Mesta, los gremios, etc. debían desaparecer y pasar directamente al control de la Corona. Esta posición distaría mucho del liberalismo propugnado por Adam Smith y defendido después con insistencia por Jardine. Para el economista escocés, el afán intermediador del gobierno en todos los ámbitos de la vida económica no representaba nada más que perjuicios para el país. Antes bien, la teoría que debería prevalecer en

6. CAMPOMANES, Apéndice a la educación popular, Madrid, Antonia de Sancha, 1775-1777, vol. IV, 1xi-lxii, nota 14.

7. JARDine, Cartas de España, p. 216. 
todas partes era la del laissez faire, por lo que era necesario que el Estado, como bien señala Jardine, dejara «que decidamos por nosotros mismos nuestros objetivos, así como la elección y el alcance de nuestros esfuerzos». ${ }^{8}$

Jardine criticaba con dureza los sucesivos planes de obras públicas planeados por los diferentes gobiernos de Carlos III. Éstos fueron principalmente de dos tipos: los caminos, que debían servir para comunicar la capital con las principales puertos marítimos del país; y los canales, que harían posible el transporte interior de mercancías entre las diferentes provincias. No es la finalidad de este estudio el describir los proyectos realizados, ni los diferentes inconvenientes que tuvieron que afrontar en su ejecución, pero es evidente que Jardine no andaba muy desencaminado al denunciar la quimera de su ejecución atendiendo a la complicada orografía peninsular, con una población tan escasa y en una situación de penuria económica como la que en ese momento atravesaba España: "[...] ya han planeado y emprendido más caminos y canales en España de los que la nación más poblada y laboriosa podría construir: tan poco conocen su propia fuerza». ${ }^{9}$

El Estado no cesaba de planificar y acometer obras gigantescas que casi nunca podía finalizar, bien por problemas de financiación o porque no existía suficiente demanda para ello. Las verdaderas reformas, parece decir Jardine, son las que se emprenden paso a paso y tienen en cuenta las verdaderas necesidades de la agricultura, la industria o el comercio. Además, éstas deben partir de un deseo y una necesidad compartida por todas las personas a las que van dirigidas, no vaya a ser que «se la impongamos por la fuerza antes de haberles enseñado a desearla». ${ }^{10}$ Esto resultaba aún más grave en un país como España, puesto que el gobierno había fomentado algunas ramas de la industria con gran perjuicio para todas las demás, restringiendo así la libertad natural y la riqueza común que pudiera derivarse de la libre competencia, y ello «sin obtener ninguna ventaja equivalente». ${ }^{11}$

Otro factor de distorsión sería también la financiación de estas empresas, máxime teniendo en cuenta las dificultades de endeudamiento que tenía la corona española. A este respecto, Adam Smith propuso como alternativa deseable el establecimiento de determinados tipos de peaje para evitar así que la construcción de los diferentes caminos y canales acabara siendo ruinosa para el promotor de las mismos, el Estado. En su opinión, el beneficio de este sistema era inmediato, puesto que «la persona que finalmente paga este impuesto, por consiguiente, gana gracias a él más de lo que pierde al pagarlo». ${ }^{12}$ Jardine señalaba que, en algún momento, se tuvo la intención de llevar a cabo algo parecido en España, pero al final acabó siendo desechado, a pesar de que sus

\footnotetext{
8. Ibidem, p. 220.

9. Ibidem, p. 320.

10. Ibidem, p. 295.

11. Ibidem, p. 241.

12. SмiтH, La riqueza de las naciones, p. 687.
} 
resultados habrían sido positivos, al haber evitado la magnificencia y la grandeza de algunos de estos planes y haber asegurado así más plenamente su ejecución.

Campomanes consideraba la Hacienda Pública como el «nervio del Estado», dado que «de todos los cuidados ninguno es tan importante, como desempeñarla». ${ }^{13}$ A pesar de ello, en una sociedad de privilegios tan marcados como la española, tanto el clero como los nobles consideraban la exención de impuestos como algo consustancial a su propia condición y a la misión que ellos estaban llamados a desempeñar en la sociedad. Una situación así, unida a la necesidad que tenía la Hacienda Pública de hacer frente a innumerables gastos militares acometidos en guerras pasadas y presentes, llevaría a Campomanes a proponer la adopción de diversas medidas. La primera de ellas era la imposición a todos los miembros del Estado del deber de contribuir a sus cargas «indistintamente, sin excepción, ni privilegio». ${ }^{14}$ Los nobles podrían conservar sus propiedades, pero sin ningún tipo de exención fiscal, excepto una simbólica de dieciséis maravedíes de vellón anuales. El mayor problema parecía proceder de la acumulación de rentas útiles y productivas en manos del clero, y, por tanto, la única solución posible requería la restricción de las adquisiciones y donaciones de las manos muertas, impidiendo así la nueva amortización de bienes por parte de la Iglesia. Esta situación condicionaba en gran medida el escaso desarrollo económico del país y el penoso estado de la Hacienda Pública, toda vez que «en un País donde los vasallos seculares sean pobres, no avrá fabricas, porque no avrá consumo; no avrá luxo [...] y cesará la industria». ${ }^{15}$

Otra cuestión importante era el abuso de la fiscalidad. En este sentido, Adam Smith denunciaba la tendencia de algunos países como España a gravar los bienes de consumo cada vez que se realizaba su venta. El ejemplo de la alcabala no podía ser más nefasto, ya que «en la mayor parte de un país donde se imponga un gravamen de estas características no se producirá nada para la venta en mercados lejanos». ${ }^{16}$ Campomanes culpaba también a este impuesto de los aumentos de precios que desanimaban las manufacturas y abogaba por la abolición de todo tipo de gravámenes que pudieran perjudicar la actividad económica. Jardine, por último, lo consideraba el más gravoso de cuantos existían en el país, dado que su aplicación a «cinco o seis ventas» podía llegar a duplicar el precio de cualquier producto. ${ }^{17}$ Según éste, su imposición arbitraria había constituido el detonante principal de la rebelión de los Países Bajos contra la Corona en el siglo XVI.

Adam Smith denunciaba también la arbitrariedad de los diezmos o de cualquier otro impuesto que se aplicara sobre la tierra, puesto que no tenían en cuenta el valor de la producción sino sólo su superficie, y servían únicamente para desalentar su posible

13. CAMPOMANES, Apéndice a la educación popular, vol. IV, p. 380, nota 356.

14. Campomanes, Escritos Regalistas. Tomo II: Juicio imparcial sobre el Monitorio de Parma, Oviedo, Junta General del Principado de Asturias, 1993, Sección Quinta, p. 121.

15. Campomanes, Tratado de la regalía de amortización, Madrid, Ediciones de la Revista del Trabajo, 1975 , p. 35.

16. SMith, La riqueza de las naciones, p. 776.

17. JARDINE, op. cit., p. 240. 
mejora. Un exceso de impuestos como el que existía en España bien podía servir para alejar el capital del país y, con ello, el cultivo de la tierra y el trabajo que ésta emplea, eliminando así las principales fuentes de ingresos de la sociedad. Para evitar situaciones como ésta, Adam Smith propondría que los impuestos no repercutieran directamente sobre el capital sino sobre los beneficios, de tal modo que recaigan no sobre el empresario que está creando riqueza sino sobre los beneficiarios últimos de todo el proceso: los consumidores. Asimismo, todo aumento en el precio de los artículos de primera necesidad debería llevar emparejado un aumento consiguiente de los salarios, de tal modo que pudiera seguir satisfaciéndose la demanda de trabajo útil. Otra idea de Adam Smith, que sería defendida posteriormente por Campomanes y Jardine, sería la de reducir el volumen de impuestos con el fin de aumentar la recaudación, dado que el fenómeno contrario sólo servía para disminuir el consumo y estimular con ello el contrabando.

Una vez planteados algunos de los problemas más acuciantes de la economía del país, es el momento de analizar sus principales repercusiones en la agricultura y la industria.

\section{LA AGRICULTURA}

La agricultura se había convertido en este siglo, de acuerdo con Rousseau, en la más respetable de todas las artes. De este modo, Adam Smith la consideraba como la parte más importante y duradera de la riqueza de cualquier nación. ${ }^{18} \mathrm{Si}$ el aumento de la producción se debe a la elevación del valor de la tierra, a su mayor productividad o a la mejora de los cultivos, éste es el mejor indicador de la prosperidad de un país. En este contexto, el panorama que presentaba la agricultura española no era nada halagüeño. La productividad era muy baja, la extensión de tierra no cultivada muy grande y los sistemas de cultivo que se empleaban tampoco estaban muy desarrollados, todo lo cual se debía en gran parte al sistema de acceso a la propiedad de la misma. Campomanes, por ejemplo, denunciaría la amortización civil o eclesiástica, por impedir el acceso a la tierra de aquellos que querían cultivarla; los arrendamientos cortos e inseguros, por ser perjudiciales para el desarrollo de la agricultura; y el nefasto papel que la tasa sobre los granos ejercía sobre la producción. Con el fin de hallar argumentos que justificaran sus planteamientos se valió de la legislación castellana y aragonesa, y propuso que los seglares tuviesen el derecho de tanteo para adquirir tierras que estuvieran en manos de la Iglesia. El sistema de propiedad era muy individualizado y subsistía junto a los señoríos y vinculaciones, separando unas zonas de otras. Además, las comunicaciones internas eran muy deficientes, a pesar de los numerosos esfuerzos ya señalados de los diferentes gobiernos ilustrados $y$, por tanto, los medios de transporte también escaseaban.

En este punto, Jardine coincidía con algunas de las opiniones de Campomanes respecto a los problemas más acuciantes y que necesitaban una solución más inmedia-

18. RousSEAU, Jean-Jacques: Emilio o la educación, Madrid, Imprenta de Alban y Compañía, 1821, p. 258. 
ta, especialmente aquellos relativos a las limitaciones de acceso a la propiedad de la tierra. La lectura previa de algunas de sus obras podría inferirse fácilmente por algunos de los datos y cifras que ofrece en sus Cartas de España. Un buen ejemplo de ello lo encontramos cuando señala que del total de las tierras del país, una tercera parte estaba en manos de la Iglesia, mientras que los dos tercios restantes o bien estaban vinculadas a mayorazgos o pertenecían a personas que eran demasiado pobres para cultivarlas adecuadamente. ${ }^{19}$

\subsection{La propiedad y el cultivo de la tierra}

Según Campomanes, la propiedad de la tierra debe ser el origen del interés y el estímulo de los campesinos, y debe repercutir necesariamente en el desarrollo de la agricultura:

Esta igualación por suertes arraíga a los vecinos: mejora por el mayor cultivo y abono de las tierras, sus cosechas; é impide enteramente el monopolio, que puede resultar, quando la labranza está reducida á cortijos, en pocas manos, y estas poderosas. ${ }^{20}$

Las vinculaciones hereditarias suponían muchas veces el abandono de la productividad y el amejoramiento de la tierra y, por tanto, era algo que sólo podía ser modificado por el soberano. Como hemos visto, Campomanes opinaba que le correspondía a éste «reglar el orden de transmitirles y cargar a las posesiones de unos en otros los impuestos y tributos, que son necesarios a la conservación de Estado, mudarlos y alterarlos conforme pidiesen la necesidad y las circunstancias». ${ }^{21}$

Adam Smith había denunciado también el derecho de mayorazgo y las vinculaciones como uno de los obstáculos más frecuentes a la libre propiedad de la tierra, al impedir la proliferación de los pequeños propietarios que, precisamente, son los más idóneos para un adecuado desarrollo y mejora de la agricultura. Jardine comparte esta opinión cuando señala que «en casi todas partes se ponen trabas a una fácil enajenación y circulación de las grandes fortunas y a una división adecuada de las grandes propiedades, al tiempo que se fomenta su acumulación mediante leyes y costumbres parciales y nocivas». ${ }^{22}$ Un resultado extremo de todo ello sería la concentración de enormes propiedades y títulos de nobleza en las manos de muy pocas personas, como ocurría con el duque de Alba o el de Medinaceli, y la solución parecía proceder, según Jardine, de algo que ya se había experimentado con éxito en Holanda, como era la promulgación de leyes que facilitaran la división de las grandes haciendas y su posterior enajenación y salida al mercado.

La reforma del tipo de arrendamiento constituía un elemento fundamental de la transformación agraria que propugnaba Campomanes. Éste debería de ser efectivo durante un largo período de tiempo y proteger al arrendatario frente al propietario de la

19. JARDINE, op. cit., pp. 232-233.

20. CAMPOMANES, Apéndice a la educación popular, vol. I, pp. 329-330, nota 10.

21. CAMPOMANES, Juicio imparcial, Sección Quinta, pp. 119-120.

22. JARDINE, op. cit., p. 346. 
tierra. Frente a esto, el contrato que más predominaba en el país era el de los arrendamientos cortos, en los cuales los propietarios podían modificar el precio de los cánones de acuerdo con su interés y con la situación del mercado. La solución pasaba, por tanto, por el alargamiento de la duración de los arrendamientos, al tiempo que se mantenía la cantidad convenida en el momento de la firma del contrato. La finalidad que perseguía Campomanes con ello era doble: por un lado, conseguir un mayor enraizamiento del campesino en la tierra que cultiva; y por otro, hacer posible una mejora de la productividad de la misma.

El control de los arrendamientos debía ser realizado por las autoridades municipales, con el fin de evitar la imposición abusiva de precios por parte de los propietarios, pero esto era siempre algo difícil de aplicar. A este respecto, tanto Jardine como Campomanes mostraban su predilección por el sistema gallego de los foros, aunque no sin algunas reticencias. ${ }^{23}$ De este modo, Jardine, al tiempo que defendía la generalización de este sistema en el resto de España, advertía también del problema que se derivaba de los subarrendatarios, los cuales eran muy numerosos tanto en Galicia como en Escocia e Irlanda, y que en muchas ocasiones reducían en exceso la tierra de labor y aumentaban las rentas en beneficio casi exclusivo de los intermediarios. El foro permitía a los campesinos el acceso directo a la tierra, perteneciendo las rentas principalmente a las instituciones eclesiásticas y a la nobleza. No obstante, el optimismo que despertara dicho sistema se vería un tanto defraudado conforme los intermediarios se fueron haciendo cargo del ochenta o noventa por ciento del total de las rentas de la tierra.

Adam Smith indicaba la necesidad de una extensión de las mejoras y los cultivos con el fin de aumentar la productividad de la tierra y abaratar los precios en el mercado. En el caso concreto de España, Campomanes abogaba por la aplicación de nuevos cultivos como las habas, la avena, o los garbanzos, dado que el campesino los consumía a pesar de continuar con el monocultivo del trigo y la cebada. La razón que justificaba esta situación era la baja productividad de la tierra en casi todo el país, a excepción de algunas zonas de regadío cercanas a los ríos y la cuenca mediterránea. Tanto es así que Jardine llega a comentar lo siguiente sobre Andalucía: «para un inglés, si exceptuamos las escasas llanuras fértiles del Guadalquivir y algunos otros ríos menores que la atraviesan, toda la región no presenta más que un aspecto estéril y desnudo». ${ }^{24}$ Los principales obstáculos para la introducción de nuevos cultivos, señalaba Jardine, eran la pobreza, la Iglesia y la falta de mercado para sus excedentes. La escasez de agua no podía servir en ningún caso de disculpa para justificar la situación puesto que, en su opinión, antiguamente se exportaban cereales del país, y estas tierras ahora baldías habían servido en otros tiempos para alimentar a un gran número de personas y de ejércitos. Sin embargo, ahora la producción actual de secano se acercaba al noventa y

23. CAMPOMAnes, Bosquejo de política económica española delineado sobre el estado presente de sus intereses, Madrid, Editora Nacional, 1984, pp. 66-67.

24. JARDINE, op. cit., p. 243. 
cinco por ciento del total y el regadío era algo muy minoritario, concentrándose principalmente en el área mediterránea, justo donde los sistemas de cultivo árabes habían pervivido en mejores condiciones.

\subsection{Los privilegios de La Mesta}

Desde la época de los Reyes Católicos, La Mesta se había visto favorecida por la legislación real y gozaba del derecho de posesión sobre cualquier terreno que en alguna ocasión hubiera sido utilizado para pasto. Esta ocupación se llevaba a cabo en forma de alquiler, pero a perpetuidad y con precios fijos, y sus representantes actuaban también como jueces en cualesquiera conflictos que pudieran surgir sobre la ocupación de las tierras. A mediados del siglo XVIII, no obstante, España había perdido ya el monopolio de las ovejas merinas, al haberse introducido éstas, con permiso de la Corona, en diversos países europeos como Suecia, Prusia o Francia, y el precio de la lana no guardaba relación con el del grano. Por tanto, la balanza comercial española empezaba a resentirse y, además, Inglaterra constituía un magnífico ejemplo de la rentabilidad de un ganado no trashumante.

Ante dicha situación, Campomanes señalaría la necesidad de establecer una ley agraria que dotara a los pueblos de tierra de labranza suficiente, recuperando los pastos y dehesas, y reclamando su derecho exclusivo a cercar sus tierras y a administrar justicia sin la intromisión de La Mesta. Jardine coincidía plenamente con estas opiniones, y apuntaba también un problema más: el obstáculo que tal organismo suponía para la replantación de árboles, cuyo reducido número sería en parte responsable de la escasez de agua. ${ }^{25}$ Los informes de los intendentes empujaron al gobierno a retirarle finalmente a La Mesta la protección de la que había estado gozando durante siglos. Para acabar con esta situación, en 1779 fue nombrado presidente de la misma el mayor enemigo de sus privilegios: Campomanes. El resultado no se hizo esperar: en 1786 se abolía el privilegio de posesión, y en 1788 , como bien señala Jardine, los propietarios fueron autorizados a cercar sus tierras y a sembrar en ellas libremente. ${ }^{26}$ Los grandes beneficiarios de la situación anterior eran fundamentalmente los nobles, que vivían en la Corte y dejaban abandonadas sus tierras de cultivo, «mientras su campo desdichado y abandonado parece destinado a estar baldío, o a estos rebaños escasos y desperdigados con sus pastores solitarios y harapientos». ${ }^{27}$

25. Ibidem, p. 300.

26. A petición de Campomanes y Floridablanca, las Cortes de 1789, reinando ya Carlos IV, trataron de algunos textos legales de tono reformista, no tributario como era su competencia habitual. De hecho, el primero sometido a consideración fue la Real Cédula de 15 de junio de 1788, que concedía facultad para cercar propiedades a los dueños de plantaciones de viñas con arbolado, olivares o huertas con frutales. El objetivo era proteger estos cultivos de los ganados, impidiendo su acceso a las fincas cerradas, y de facto suponía una afirmación del derecho individual de la propiedad de la tierra al suprimir derechos colectivos.

27. JARDINE, op. cit., p. 306. 


\subsection{Las nuevas colonias: Un ensayo ilustrado}

Una de los experimentos más interesantes llevados a cabo en el siglo XVIII para fomentar el desarrollo agrícola y aumentar la población fue la creación de nuevas colonias en Andalucía. Se trataba de repoblar zonas deshabitadas con colonos extranjeros. Estas nuevas poblaciones, cuyo Fuero fue redactado en 1767, se asentaron en diferentes partes de esta región y tuvieron como uno de sus principales impulsores, aparte de Pablo de Olavide, al propio Campomanes. ${ }^{28}$ Los colonos recibieron tierras, casas, aperos y animales de labranza a cambio de pasar una renta a la Corona, con la prohibición expresa de una posterior vinculación, hipoteca o división de las mismas. Además, ninguna otra institución religiosa que no fuera la propia iglesia parroquial podía tener entrada en ellas. Los objetivos que se perseguían con estos asentamientos eran los de colonizar zonas, como Sierra Morena, que habían estado desérticas anteriormente, aumentar la población útil y la producción agraria, y disminuir la inseguridad de las comunicaciones entre Madrid y Andalucía, aumentando así el aprovisionamiento y la seguridad de los transeúntes. La filosofía que se escondía detrás de esta propuesta era la de desarrollar una sociedad igualitaria, a través de explotaciones agrarias de tamaño mediano y de labradores independientes, cuya producción se vería libre de la pesada carga de unos impuestos demasiado elevados. No obstante, los frutos no fueron tan optimistas como cabría haber esperado, y Jardine se iba a encargar nuevamente de predecir el abandono de estas colonias una década tan sólo después de su creación:

Los contratos iniciales del gobierno con estas pobres gentes empiezan a ser infringidos ahora, lo cual probablemente traerá pronto la ruina al asentamiento, y devolverá de nuevo estos pequeños lugares al desierto que les rodea..$^{29}$

Los problemas que tuvieron que afrontar estos asentamientos eran de muy diversa índole, e iban desde la desidia y el incumplimiento del gobierno, ya citados por Jardine, pasando por una elección errónea de las personas encargadas de su cultivo, hasta el mismo recelo mostrado por la autoridad religiosa ante la labor emprendida por Olavide. A pesar de todo, como apunta Jardine con ironía, «no resulta fácil de imaginar el enorme placer que supone el encontrar aquí leche, mantequilla y queso».

\subsection{Las manos muertas y la reforma agraria}

Montesquieu había hecho referencia en El espíritu de las leyes a la necesidad de limitar las propiedades del clero. En su opinión, esta limitación no debería hacerse mediante leyes, sino mediante el convencimiento previo y la concesión de un derecho de indemnización sobre la adquisición de las manos muertas. Para ilustrar la necesidad de tales medidas opone el ejemplo de Castilla, donde no existen tales normas y «el

28. Publicado el 5 de julio de 1767, el 17 de agosto se inició la colonización propiamente dicha en el Convento de La Peñuela, que a partir de 1770 pasó a denominarse La Carolina. Vid. CASTILlo Soto, Josefina: «Las nuevas poblaciones de Sierra Morena bajo la superintendencia de don Pedro Pérez Valiente: oficios y colonos», en Espacio, Tiempo y Forma, Serie IV, vol. V, 1992, pp. 283-296.

29. JARDINE, op. cit., p. 282. 
clero lo ha invadido todo», al de Aragón, donde este derecho ha sido aplicado en cierta medida y el clero ha adquirido menos propiedades. ${ }^{30}$

Según el catastro de Ensenada, la Iglesia poseía el 14’7\% de las propiedades de Castilla, lo cual equivalía al 24 ' $1 \%$ del producto total de la misma, con lo cual, si a esto le sumamos el ganado, el pago de los intereses, los diezmos y los demás ingresos, percibía la mitad de toda la renta líquida del Estado. Por tanto, cuando una norma había derivado en tal abuso era necesario proceder a su abolición con el fin de corregirlo. Y esto es lo que van a proponer algunos de los ilustrados españoles, en especial Campomanes. Su Tratado de la regalía de amortización (1765) fue escrito para intentar solucionar el problema de las manos muertas, agudizando el conflicto ya existente entre la Iglesia y el Estado durante la segunda mitad del siglo XVIII. Los reformistas ilustrados, que se presentaban normalmente como devotos cristianos deseosos de restaurar la disciplina y simplicidad primitivas de la Iglesia, tomarían este escrito como punto de partida para apoyar la necesidad de reforma, y el derecho que asistía al rey para llevarla a cabo.

La posición de Campomanes distaba mucho de cualquier radicalismo, ya que una abolición de los privilegios que hacían posible la concentración de la propiedad en manos del clero y de la nobleza se acabaría enfrentando con el mantenimiento del régimen político de monarquía absoluta que éste defendía. Lo que cabía hacer en tal situación era limitar de forma gradual el crecimiento de estas propiedades, al tiempo que se estimulaba la labranza de los terrenos baldíos y se regulaban los arrendamientos. El reparto de la tierra contribuiría, de este modo, a una mayor estabilidad social y a un aumento consiguiente de su productividad. La solución pasaría, según Campomanes, por la adopción de una serie de medidas fundamentales como las siguientes: evitar que las amortizaciones futuras recaigan de nuevo en manos muertas; promulgar una ley que obligue a algunos terratenientes a arrendar sus tierras excedentes; distribuir las tierras comunales entre los campesinos que estén dispuestos a trabajarlas; exigir la implantación de arrendamientos largos y de precios vigilados; y, por último, igualar el reparto de la tierra en los nuevos asentamientos. En este contexto, cualquier otra solución se situaba, por tanto, al margen de las posibilidades políticas de la monarquía española del siglo XVIII.

Los frutos más importantes de esta labor se dejarían ver, en la siguiente generación, con la aparición del Informe de Ley Agraria de Gaspar Melchor de Jovellanos, obra auspiciada por la Sociedad Económica Matritense y leída en la misma en 1794, que acabaría siendo denunciado por el Santo Oficio e incluido en el Índice de Libros Prohibidos. No obstante, habían pasado ya muchos años desde el anterior Expediente, y las circunstancias políticas eran ahora contrarias a la promulgación de una ley agraria, por lo que Jovellanos recomendaría por contraproducentes la supresión de muchas de las leyes existentes en ese momento. Su enfoque se basaba principalmente en los

30. Montesquieu, Barón de [Charles de Secondat]: El espíritu de las leyes, Barcelona, Orbis, 1984, pp. 380-381. 
planteamientos realizados por Adam Smith sobre la búsqueda del interés individual y de una mayor libertad económica.

Existiría, no obstante, una abundante legislación agraria anterior a este periodo, especialmente tras los graves incidentes de 1766, que es cuando el gobierno se decidió a tomar algunas medidas que ayudaran a paliar el problema. De este modo, en abril de aquel año, siendo Campomanes fiscal del Consejo de Castilla, se repartieron tierras de propios a los vecinos de la provincia de Badajoz, empezando por aquellos que estaban más necesitados. Al mismo tiempo, se ordenaba seguir el ejemplo en otros pueblos de Extremadura, Andalucía y La Mancha. Dicha experiencia, sin embargo, sirvió para caer en la cuenta de la inutilidad de darle tierras a los que no sabían cultivarlas, por lo que acabó dándose preferencia a los labradores dueños de yuntas y sin tierras que cultivar. De cualquier modo, los frutos de todo ello fueron muy escasos, por no decir nulos, debido principalmente a la inexperiencia de los nuevos propietarios y a la presión que ejercían los antiguos oligarcas para que no se aplicasen las nuevas leyes o lo hicieran a su favor.

Jardine sólo se iba a distanciar un tanto de Campomanes a la hora de prestar una especial atención a tres cuestiones fundamentales: la necesidad de mejorar las leyes, la conveniencia de una forma de gobierno más representativo, y la concesión de mayores estímulos a los propietarios para que vivan más tiempo en sus fincas. Sobre esto último nos contaría una curiosa anécdota bien ilustrativa de la situación de abandono del campo español:

Sólo conozco a un caballero de esta provincia que tenga el gusto y la resolución suficientes para vivir casi todo el tiempo en su hacienda del campo, pero [apostilla Jardine con asombro] tolera que su esposa viva en la ciudad. ${ }^{31}$

\section{LA INDUSTRIA}

Montesquieu había apuntado la necesidad de fomentar la industria para estimular el consumo y favorecer un mayor crecimiento de la población. A este respecto, Jardine, señalaba que la abundancia de dinero en España suponía el principal factor de distorsión para cualquier posible establecimiento industrial. Mientras éste abunde, «no servirá para fomentar la aparición de la industria sino para impedirla, y para empobrecer a la gente al disminuir su esfuerzo». ${ }^{32}$ Por desgracia, para cuando el país se diera cuenta de ello, continúa Jardine, sería ya demasiado tarde, puesto que ya existiría entonces una industria establecida en países más competitivos.

Campomanes advertía que la verdadera riqueza no era otra cosa que «el aprovechamiento y abundancia de los frutos y producciones del país» $\mathrm{y}$, por tanto, el trabajo era una obligación ciudadana que debería conducir a éste a un cierto nivel de prosperidad. ${ }^{33}$ Así pues, era necesario un aumento de la población y de la productividad

31. JARDINE, op. cit., p. 390.

32. Ibídem, p. 194.

33. CAMPOMANES, Apéndice a la educación popular, vol. IV, xii. 
que hiciera posible el crecimiento de la industria. Un mayor número de habitantes traería consigo un mayor número de contribuyentes, mayor capacidad militar, mayor producción y consumo y, por consiguiente, un aumento del poder y la riqueza del país. Algunos condicionantes negativos de la productividad económica eran el gran número de festividades que había anualmente, noventa y tres en el caso de los artesanos; la falta de empleo para las mujeres; y el elevado número de mendigos y ociosos que había repartidos por todo el país. Resulta destacable como en este punto, al menos, Campomanes situaba a las mujeres en un plano de igualdad con los hombres: «La muger tiene el mismo uso de razon, que el hombre: solo el descuido, que padece en su enseñanza, la diferencia, sin culpa suya»..$^{34}$

Su capacidad para desempeñar los diversos oficios era idéntica a la de los hombres, como idéntica era también su capacidad de entendimiento y de aprendizaje, antes bien «la muger bien educada, no cede en las luces, ni en las disposiciones á los hombres; pero en las operaciones manuales, es mas agil que ellos». ${ }^{35}$

Por tanto, resultaba urgente emprender no sólo una reforma de las diferentes ramas de la economía, sino también una revisión de los valores morales y prejuicios de los españoles hacia el trabajo, con el fin de devolver a éste la estima que debía tener entre el pueblo. El trabajo constituía el único remedio contra la pobreza y era, asimismo, el origen del crecimiento de las virtudes sociales. Campomanes respetaba cualquier actividad industrial con tal de que fuera capaz de generar empleo, aunque manifestaba su preferencia por todas aquellas que fueran compatibles con el desarrollo de la agricultura. Era necesario, pues, fomentar dos tipos de industria: la rural, que debería procurar unos mayores ingresos y un mayor bienestar al agricultor; y la urbana, más «fina», donde los salarios eran más altos y existía una mayor demanda de productos manufacturados.

Campomanes señalaba también la necesidad de replantearse la política de desarrollo de las manufacturas reales emprendida por los primeros Borbones, así como la necesidad de ir dando paso a un mayor fomento de las particulares. A este respecto Jardine, aún reconociendo el esfuerzo emprendido por los diferentes gobiernos reformistas, señalaba su escaso éxito, debido especialmente a su excesivo afán intervencionista. El gobierno, viene a decir Jardine, o bien no entendía cómo había que afrontar la situación, o bien no tenía interés alguno en cambiarla. En su opinión, parecía estar más cerca de lo segundo, por lo que cualquier intento de crear las condiciones que hicieran posible un mayor desarrollo de la industria tenía que pasar primero por la abolición del sistema de gobierno y su sustitución por uno más democrático y más acorde con las características y necesidades del país.

34. CAMPOMANES, Discurso sobre la educación popular de los artesanos y su fomento, p. 367.

35. Ibidem, p. 369. 


\subsection{Las regulaciones gremiales}

Una de las limitaciones al desarrollo de la industria que iba a generar un mayor número de controversias era la referida a los gremios. Éstos se habían multiplicado hasta el punto de que «todo oficio estaba monopolizado en cada ciudad por un grupo que trabajaba siguiendo un reglamento establecido por el Gobierno, y que especificaba minuciosamente la naturaleza de los procedimientos y de los productos» ${ }^{36}$ Estos gremios se encontraban, además, en manos de los maestros, quienes utilizaban su posición para explotar a los aprendices y mancebos, y para obstaculizar la introducción de cualquier novedad en su oficio. Limitar este poder formaba parte, por tanto, del propósito mercantilista de una economía unificada bajo control estatal, y coincidía con el esfuerzo general de los reformistas españoles por establecer la supremacía del Estado sobre todas las facetas de la vida nacional. El mayor defensor de esta postura era el regalista Campomanes, para quien

[...] qualquiera excepcion de las reglas, que deben ser comunes á todos, perjudica al estado, y perturba notablemente el buen gobierno: inconveniente que se tocará, siempre que los artesanos obtengan fueros particulares, ó se substraigan de la policía general, y ordinaria. $^{37}$

Adam Smith sería también un decidido defensor de la abolición de todos estos privilegios, dado que restringían la competencia al limitar el número de personas que podían ser empleadas en un oficio, e iban en contra de la libertad tanto del trabajador como del patrón. El efecto contrario conllevaría una reducción de los beneficios de los maestros y de los salarios de los operarios, con la consiguiente bajada en el precio de los productos y la posibilidad de que un mayor número de personas pudieran acceder a su consumo. No obstante, a pesar de su escepticismo ante la capacidad del Estado para poner fin a esta situación, «tampoco debería hacer nada para facilitar esas agrupaciones; y mucho menos para volverlas necesarias». ${ }^{38}$

Campomanes atacó ferozmente a los gremios por su regulación exclusiva, su utilización de métodos excesivamente tradicionales y su ignorancia. Defendía la abolición de las ordenanzas que éstos imponían y que coartaban la libertad de trabajo. Estas ordenanzas gremiales eran algo contrario a la jurisdicción ordinaria y, por esa razón, debían ser revisadas por las autoridades locales con el fin de hacerlas compatibles con los derechos públicos y el desarrollo de las manufacturas, debiendo posteriormente el Consejo dar su aprobación. Los tributos que los artesanos debían pagar para ingresar en los gremios les arruinaban, al tiempo que empobrecían y atrasaban los oficios, creando pleitos y discordias familiares. Los gremios y cofradías gremiales imponían contribuciones muy gravosas a los artesanos sin contar con la debida licencia del soberano y, por tanto, se hacía necesario, según Campomanes, restablecer todos aquellos atributos que éste tenía conferidos por razones históricas.

36. HERR, Richard: España y la Revolución del Siglo XVIII, Madrid, Aguilar, 1988, p. 105.

37. CAMPOMAnES, Discurso sobre la educación popular de los artesanos y su fomento, ii.

38. SMith, La riqueza de las naciones, p. 191. 
De este modo, el gobierno intentó ir debilitando el exclusivismo de los gremios y aumentar las manos útiles entre la población. Con ese fin, se enseñaron oficios útiles a los niños de los asilos, se promovieron escuelas donde se enseñaron algunos oficios, y se autorizó a las mujeres a que se emplearan en cualquier oficio adecuado a su fuerza física, todo ello en contra de las propias reglamentaciones de los gremios. Es más, en 1777 los gremios fueron obligados a admitir a artesanos extranjeros con tal de que fuesen católicos y que demostrasen la debida competencia en el oficio. También, y por influencia de Campomanes, se trató de hacer desaparecer la «mala fama» que envolvía al trabajo manual, autorizando para ello a los hidalgos a que se dedicaran a los oficios, haciendo compatibles diversas ocupaciones con la condición de noble y el desempeño de cargos públicos. Sin embargo, a pesar de tanta buena voluntad, Jardine se mostraría nuevamente bastante pesimista, especialmente al señalar que «una vez que se establece cualquier abuso sobre la base firme del interés de cualquier grupo influyente de personas, éste resulta entonces casi inamovible». ${ }^{39}$

\subsection{Las sociedades económicas}

Resulta evidente que Campomanes puso gran parte de sus esperanzas de regeneración del país en el fomento de las Sociedades Económicas. De este modo, en 1763 envió al primer ministro Grimaldi, para que éste se lo presentara al rey, un plan detallado en el que se proponía su constitución en todo el país. Y tan sólo un año más tarde vería la luz la primera de todas ellas, la Real Sociedad Bascongada de Amigos del País, cuyas reuniones alcanzaron una gran difusión, y que bien pronto se distinguiría por la adopción de algunas medidas bastante eficaces para fomentar artes útiles como la agricultura, el comercio y la industria. Gracias al éxito de su labor, Campomanes la tomaría como modelo en su Discurso sobre el fomento de la industria popular (1774). Como ya hemos visto, con la creación de estas Sociedades se pretendía que la nobleza y el clero participaran en el desarrollo del país, mediante el fomento de la agricultura y la industria.

Un año más tarde, el propio Campomanes completaría su visión del problema con la publicación de su Discurso sobre la educación popular de los artesanos y su fomento (1775), en el que aboga por la creación de diferentes centros que puedan servir para divulgar el conocimiento de los últimos adelantos científicos y tecnológicos, así como una academia de las Ciencias que se ocupe del fomento y difusión de la industria y el comercio. El aprendizaje constituiría la etapa más dura e importante en la formación del artesano y, por ello, era necesario evitar la rutina en la adquisición de conocimientos y mejorar los métodos de enseñanza. La educación se convierte así, para Campomanes, en un instrumento esencial no sólo para mejorar la educación del pueblo sino también para incorporar a la parte más ociosa de la sociedad en el desarrollo económico del conjunto, mediante su ocupación en aquellas labores que puedan

39. JARDINE, op. cit., p. 248. 
más útiles y provechosas, ya que «no basta que las cosas sean necesarias y útiles: es preciso conocerlas, y saberlas aplicar por reglas y sistema ordenado á cada oficio»». ${ }^{40}$

La importancia atribuida a las Sociedades Económicas era tal que Campomanes las consideraría las únicas capaces de determinar en qué situación se encontraban las provincias de la Corona, así como la industria que era más necesaria en cada una de ellas. Entre 1775 y 1778 se aprobaron alrededor de cincuenta Sociedades, y se realizaron un número de solicitudes bastante mayor. La labor que éstas desarrollaron estaba centrada en el ámbito de la educación profesional de los niños desocupados, aunque sirvieran también para realizar diversos informes de carácter económico. No obstante, y lamentablemente, casi ninguna de las múltiples Sociedades que se crearon a continuación llegaron a desempeñar actividad alguna de gran relevancia. Por tanto, la uniformidad que Campomanes pretendía instaurar sólo fue posible en la redacción de sus estatutos, ya que la cantidad y calidad de las actividades emprendidas por éstas fue muy desigual. Sea como fuere, tal como señala Llombart, estas instituciones funcionaron como «cajas de resonancia de las ideas de una ilustración que en general pensaba que el progreso y la felicidad dependían en gran medida de las decisiones de la monarquía». ${ }^{41}$

El optimismo de Campomanes no tardaría, por tanto, en verse defraudado. Jardine se daría cuenta de la situación y criticaría su mal funcionamiento, del cual sólo salvaba a la Sociedad Bascongada, y ello debido al talento de su principal responsable, Javier María de Munibe, conde de Peñaflorida. Según Jardine, el gobierno, a pesar de ser el principal responsable de su creación, se había convertido ahora en causante de su decadencia, puesto que «no las ha impulsado mucho últimamente, a pesar de su intención inicial de darles protección». ${ }^{42}$ Sempere y Guarinos, contemporáneo suyo, señalaba también la abierta y permanente hostilidad que muchos tribunales y ayuntamientos les mostraban, al no ver en ellas otra cosa que rivales en su lucha permanente por recibir el favor del rey. ${ }^{43}$ Una de las consecuencias más notorias de los ataques recibidos por parte de algunos de los religiosos más intransigentes fue la posterior entrada masiva del clero en las mismas, y así encontramos que, en 1789, cinco de ellas tenían como director a un obispo y otra a un fraile. Jardine denunciaría esta nueva situación al ver en ella una de las principales causas de su escasa importancia actual, ya que los clerigos «toman el control de todo, y se han convertido en dispensadoras de pequeños premios a maestros de poca monta por enseñarles a unos cuantos niños el catecismo». ${ }^{44}$

El panorama que nos presenta no podía ser más desalentador, especialmente al tratarse de una idea en la cual Campomanes y gran parte de los ilustrados habían puesto

40. CAMPOMAnES, Discurso sobre la educación popular de los artesanos y su fomento, p. 64.

41. LlOMBART, Vincent: Campomanes, economista y político de Carlos III, Madrid, Alianza Editorial, 1992, p. 287.

42. JARDINE, op. cit., p. 329.

43. SEMPERE y GuARINOS, Juan: Ensayo de una biblioteca española de los mejores escritores del reynado de Carlos III, Madrid, Gredos, 1969, vol. V, p. 148.

44. JARDINE, op. cit., p. 329. 
sus mejores esperanzas de regeneración. De cualquier modo, es justo señalar que incluso en el peor de los casos, sirvieron para difundir el espíritu de la Ilustración mediante la creación de nuevas bibliotecas y la traducción de libros extranjeros, y prestaron una especial atención a los temas económicos con la elaboración de múltiples propuestas e informes que posteriormente fueron elevados al gobierno.

\section{EL EJEMPLO BRITÁNICO}

Como hemos visto, Jardine ofrecía una imagen de la economía española de finales del siglo XVIII bastante más pesimista que el que manejan hoy los historiadores españoles y la opinión generalizada de los ilustrados de la época. ${ }^{45}$ No cabe duda que esta perspectiva estaba condicionada por la realidad de la que partía: una Gran Bretaña con un gran dinamismo social, político y económico que estaba camino de convertirse en un nuevo imperio. En este país se concitaban diferentes factores característicos del éxito: una cierta efervescencia científica y cultural, un sistema político que permitía la crítica y proporcionaba unas elevadas cotas de libertad, una monarquía sujeta al control de un parlamento electo y, quizás como consecuencia, un gran desarrollo agrícola, industrial y comercial. Todo ello en un contexto en el que liberalismo económico iba cobrando fuerza teórica y aplicación práctica, mientras que en España aún seguían defendiéndose sin ambages muchos de los principios y las prácticas mercantilistas.

El hecho de realizar una descripción de la realidad española viniendo de otro país, otra lengua y otro nivel de desarrollo económico, político y cultural, le permite a Jardine centrarse en lo esencial y dejar de lado lo anecdótico, al tiempo que le permite ofrecer una perspectiva de los usos y costumbres de la sociedad que describe sin el matiz de lo ya conocido y, por tanto, de lo aceptado sin más como propio. Esto le permite afirmar que la decadencia española tenía un origen indiscutiblemente político y se debía principalmente al despotismo y la falta de tolerancia de una monarquía absoluta que, con frecuencia, se apoyaba en los privilegios de la aristocracia y la iglesia para mantener al pueblo sometido a la ignorancia, la pobreza y, con frecuencia, a la opresión. Estas ideas casarían difícilmente con el posibilismo reformista de los mejores ilustrados españoles, como Jovellanos, pero eran indicativas de una forma de ver la realidad que fraguaría en dos acontecimientos que habrían de transformar radicalmente el mundo: la declaración de Independencia de los Estados Unidos de América y el triunfo de la Revolución Francesa. No sorprende seguir la trayectoria vital de Jardine y comprobar su poco disimulada simpatía hacia ambos procesos históricos.

En España hacía falta, por tanto, una transformación profunda del sistema político que permitiera, junto a un liberalismo económico, una mayor tolerancia religiosa, una apertura del comercio y, en definitiva, un gobierno representativo, elegido por el parlamento y garante de las libertades civiles. Sin ello, apuntaba Jardine, cualquier intento

45. Vid. ANES, Gonzalo: «La economía española en el siglo XVIII», en Economía y economistas españoles, vol. 3: La Ilustración, Barcelona, Círculo de Lectores-Galaxia Gutenberg, 2000, pp. 91-184; y LLOMBART, op. cit. 
de reforma, como la emprendida por los sucesivos gobiernos de Aranda, Campomanes o Floridablanca, resultaba inútil y apenas podía servir para paliar en parte la situación de decadencia en la que estaba sumido el país. En realidad, como sabemos, la deriva que tomaron las autoridades del país durante el reinado de Carlos IV, especialmente tras el triunfo de la Revolución Francesa, fue justo la contraria y la historia nos sirve de fiel testigo del devenir de los acontecimientos y de sus consecuencias. España, por desgracia, no sólo no llevaría a cabo las reformas propuestas por personas como Jardine, o Campomanes, o tantos otros ilustrados españoles y del resto de Europa, sino que se encerraría aún más en una situación tan singular de aislamiento, intolerancia y mantenimiento de los privilegios para unos pocos, con consecuencias nefastas para el desarrollo político y económico del país durante todo el siglo XIX. 